\title{
Assessment of atmospheric ultrafine carbon particle-induced human health risk based on surface area dosimetry
}

\author{
Chia-Pin Chio, Chung-Min Liao* \\ Department of Bioenvironmental Systems Engineering, National Taiwan University, Taipei 106, Taiwan, ROC
}

\section{A R T I C L E I N F O}

\section{Article history:}

Received 18 March 2008

Received in revised form 9 July 2008

Accepted 19 August 2008

\section{Keywords:}

Ultrafine carbon particles

Human health

Risk assessment

Surface area dosimetry

\begin{abstract}
A B S T R A C T
Evidence shows a strong correlation between human mortality/morbidity and atmospheric ultrafine carbon particle (UFCP with aerodynamic diameter $<18 \mathrm{~nm}$ ). Theoretical and experimental studies have attempted to use mass concentration/dose as exposure dosimetry to construct the dose-response relationships. Yet little attention has been given to the problem of using surface area dosimetry in UFCP-related risk assessment. We introduced an integrated risk assessment framework based on surface area dosimetry to estimate the adverse health potential risk exposed to atmospheric UFCP. We used the neutrophil cells elevation effect as adverse health effect endpoint. We reanalyzed the published data of UFCP particle diameter $(d p)$ and associated specific surface area (SSA) to reconstruct their relationship through log-linear regression method. Our results show that smaller particle size $(d p<51 \mathrm{~nm})$ demonstrated steep slope (ln SSA $=11.0-2.03 \ln d p)$, whereas larger particle size $(d p>51 \mathrm{~nm})$ was found close to the theoretical relationship (ln $\mathrm{SSA}=8.65-1.20 \ln d p$ ). We applied the modeled relationships to estimate the surface area doses of human inhaled particles in specific scenarios or subgroups. Our findings show that Adult and Youth subgroups in northern Taiwan region posed the highest potential risk, indicating that the median 10\% exceedance risks are 39.6 (95\% CI: 36.4-42.9) fold compared to control based on neutrophil cells elevation effect. The result provides a preliminary aspect for discussing the human health adverse effect exposed to atmospheric UFCP for specific groups based on particle surface area dosimetry.
\end{abstract}

(c) 2008 Elsevier Ltd. All rights reserved.

\section{Introduction}

Epidemiological studies have revealed that ambient particulate matter (PM) concentrations and negative health impacts, such as asthma, hospital admissions, and premature mortality, are inextricably linked. The relationships between air pollutants and respiratory/cardiac diseases were found in several emergency room studies in Taiwan (Hwang et al., 2004), France (Nerriere et al., 2005), Canada (Yang et al., 2005), and USA (Wilson et al., 2005). Utell and

\footnotetext{
* Corresponding author. Tel.: +886 22363 4512; fax: +88622362 6433.

E-mail address: cmliao@ntu.edu.tw (C.-M. Liao).
}

Samet (1996) indicated that the potential mechanisms for induction of an inflammatory response attributed to: (i) ultrafine particle (UFP, i.e. particle with aerodynamic diameter less than $0.18 \mu \mathrm{m}$ (Fine et al., 2004)), (ii) transition metal ions and (iii) aerosol acidity. Hence, a lot of UFPs play an important role for causing human adverse effects. Chow and Watson (2006) categorized the toxicological endpoints for human or animal exposing to UFPs into five classes of cell counts, enzymes, cytokines, bronchoalveola lavage fluid (BALF), and DNA damage.

Generally, the carbon content is the most abundance element of particle in the ambient environment. Particulate matter contained nearly 50\% (Li and Lin, 2003), 33-42\% (Chio, 2005), and 17-25\% (Lee et al., 2005) of carbonaceous materials measured in northern, central and southern 
Taiwan, respectively. Therefore, PM contained carbon materials should be severe problem to human, especially for ultrafine carbon particle (UFCP) due to their relative large surface area compared to fine or coarse carbon particle (Kim et al., 2005; Stoeger et al., 2006). The large surface area of UFP or UFCP might play an important role causing more severe health effect (Oberdörster et al., 2005; Stoeger et al., 2006). In light of the above mentioned studies, surface area was selected as the key dosimetry in our study.

The carbon contents included organic matter, elemental carbon (EC) and inorganic carbon emitted largely from fossil fuel combustion, biomass burning, residential coal combustion, biogenic emissions, and secondary sources (Watson et al., 2006). Yet carbon black (CB) is a powdered form of EC that is manufactured by using hydrocarbons pyrolysis process. Over 90\% CB production in the world is used for the reinforcement of rubber, and the other remaining is used for printing inks, paints, lacquer, and additives for industry (IARC, 1996; Tsai et al., 2001; Wellmann et al., 2006). The annual consumption rate of $C B$ in Taiwan was nearly 113,000 tons $\mathrm{yr}^{-1}$. $90 \%$ of them were used domestically (Tsai et al., 2001). The International Agency for Research on Cancer (IARC, 1996) have addressed the $\mathrm{CB}$ as a group $2 \mathrm{~B}$ (possible human carcinogen) based on the development of lung tumors in rats expose to $C B$ chronically.

Evidence showed that the workers in CB manufacture plant, highway toll station, and dockyard posed potential human health risks (Morfeld et al., 2006; Wellmann et al., 2006). Mauderly et al. (2000) demonstrated the similar pulmonary carcinogenicities of $\mathrm{CB}$ and diesel soot in rats exposed heavily for two years. Soot is the residue from incomplete combustion of carbon-containing material, and varies widely in composition and physicochemical properties. These contained carbon particles would be released through tire wearing and oil burning processes emitted from vehicles (Mauderly et al., 2000). ten Brink et al. (2005) also indicated that the fraction of EC in the ultrafine level is approximately $40 \%$ by using an approach with filter and impactor sampling methods. Because the effects of ultrafine $\mathrm{CB}$ and UFCP inhaled could be similar, we intended to assess the UFCP-induced adverse health risk from ambient environment using the biological effects exposed to $C B$.

The objectives of this study are threefold: (i) to assess the surface area-based cumulative dose of UFCP exposure from atmospheric environment; (ii) to reconstruct and verify the suitable dose-response profiles to describe the relationship between UFCP and human health effects; and (iii) to estimate the exceedance risk curves to susceptible subgroups or specific scenarios. Toward these goals, we reanalyzed several datasets measured throughout Taiwan regions and used an integrated method to estimate cumulative doses of different settings. Monte Carlo (MC) analysis and human respiratory tract (HRT)/multiple path particle dosimetry (MPPD) models (ICRP, 1994; CIIT Centers for Health Research, 2006) are introduced. HRT model is used for determining the probabilities and uncertainties of exposure doses from atmospheric environment. The MPPD model is used for assessing the internal dose of human lung. We also provided a framework to assess the exceedance risk profiles based on the toxicological endpoints from bioassays for protecting and early warning of the human health.

\section{Materials and methods}

We divided the probabilistic risk assessment (PRA) framework into four parts (Fig. 1) and will be described in detail in the subsequent sections.

\subsection{Problem formulation}

Studied designs included the northern, central, and southern Taiwan regions, denoting as NT, CT, and ST, respectively (Figs. 1A and 2). Three age groups (Adult, Youth, and Infant) and four activities (indoor (In), sleep (SI), outdoor ( $\mathrm{Ou})$, and in-traffic (Tr)) are taken into account for exposure assessment. We divided the study area into three regions of Taiwan (NT, CT, and ST) because these three regions had different characteristics, especially for populations, vehicles, and industrial sources. Hence, we considered that assessing the risk in individual city or region was necessary. Based on the volume of air breathed rate, we also considered that these age groups (Adult, Youth, and Infant) are significantly different. On the other hand, different activities with associated time spent should be taken into account for modeling the real conditions.

The excellent available published $\mathrm{PM}_{0.18}$ data in Taiwan conducted from the previous study (Chio et al., 2007) was divided into several settings representing (i) different regions in Taiwan (NT, CT, and ST) and (ii) different activities (In, Sl, Ou, and Tr) within those regions (Fig. 2).

\subsection{Exposure assessment}

The precise estimation for particle surface area is crucial, because it affect the quantification of the surface area-based exposure dose significantly (Fig. 1B). We could obtain the surface area of particle through BET (Brunauer, Elmmett, and Teller) method (Brunauer et al., 1938). The particle diameter can be measured using transmission electron microscopy (Renwick et al., 2004; Stoeger et al., 2006). Here, we reconstructed the empirical relationship between particle size and corresponding surface area based on previous published data (Table 1 ). The specific surface area (SSA) is defined as particle surface area (SA) divided by particle mass $(m)$,

$\mathrm{SSA}=\frac{\mathrm{SA}}{m}=\frac{\pi(\eta d p)^{2}}{\frac{1}{6} \rho \pi(\eta d p)^{3}}=6(\rho \eta)^{-1}(d p)^{-1}$,

where $\rho$ is the density of particle, $\mathrm{SA}=$ $\pi(\eta d p)^{2}, m=1 / 6 \rho \pi(\eta d p)^{3}, \quad \eta$ is the sharp parameter of particle diameter $(d p)$. A natural log linear function between SSA and $d p$ can be rewritten, leading to

$\ln [\mathrm{SSA}]=\ln \left[6(\rho \eta)^{-1}\right]-\ln [(d p)]$.

Therefore, we selected an appropriate function based on the above descriptions to fit the previous published data (Table 1), 


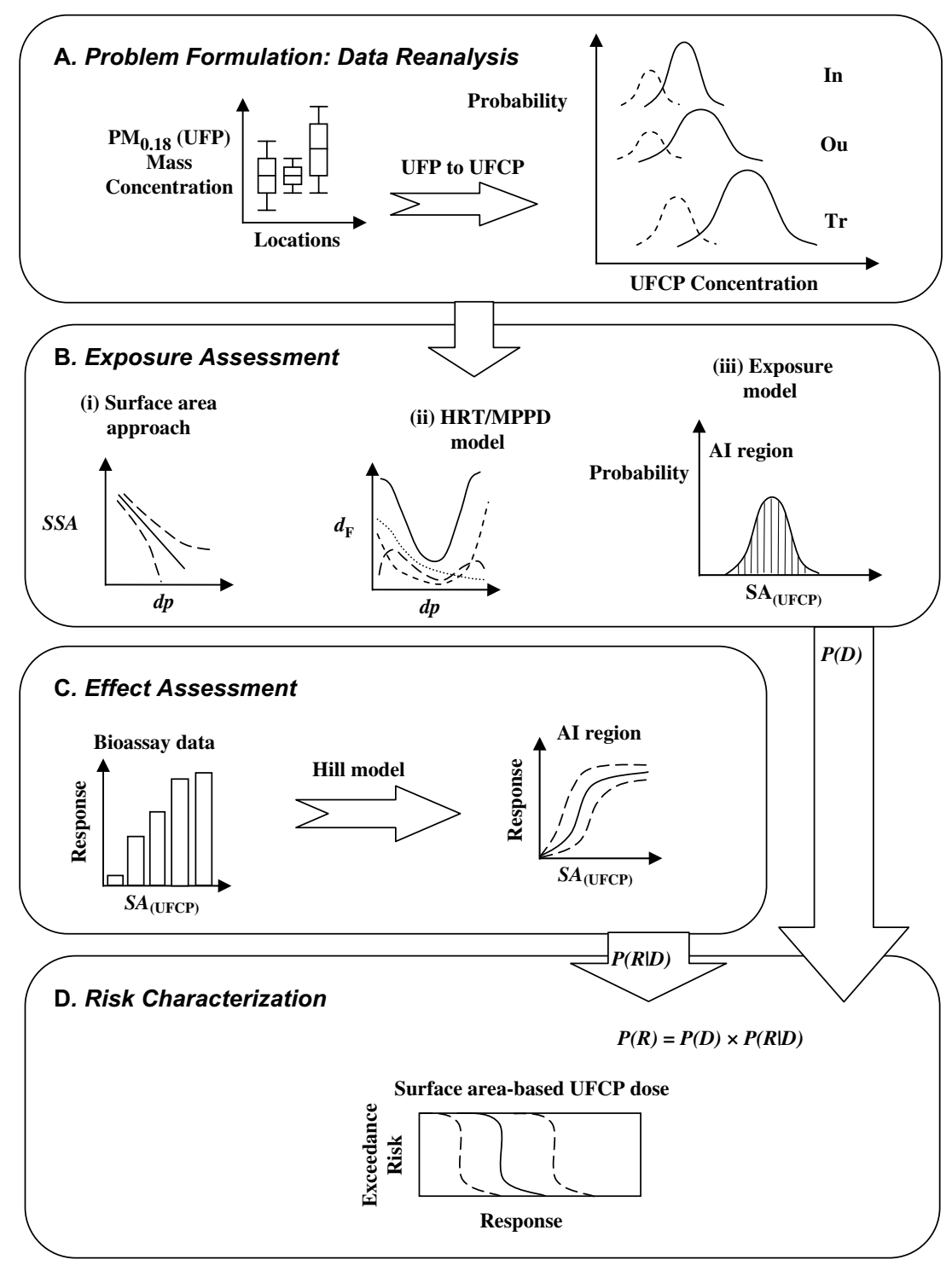

Fig. 1. Schematic diagram of the proposed probabilistic risk assessment framework in this study. The full names of all the abbreviated words in the figure are presented in the main content.

$\ln Y=a+b \ln X$

where $Y$ is the size-dependent SSA of particle (dependent variable), $X$ is the particle diameter $(d p)$ (independent variable), $a$ is the interception of the linear fitted model, and $b$ is slope of the linear fitted model.

The upper and lower 95\% confident limit level for the fitted linear model is also considered as,

$\widehat{Y}_{h} \pm t(1-\alpha / 2 ; N-2) s\left\{\widehat{Y}_{h}\right\}$

$s\left\{\widehat{Y}_{h}\right\}=\operatorname{SQRT}\left[\operatorname{MSE} \times\left(\frac{1}{N}+\frac{\left(X_{h}-\bar{X}\right)^{2}}{\sum\left(X_{i}-\bar{X}\right)^{2}}\right)\right]$,

where $\widehat{Y}_{h}$ is the predicted mean value, $t(1-\alpha / 2 ; N-2)$ is a value of the $t$-distribution with $N-2$ degrees of freedom, $\alpha$ is the proposed significant level (here is equal to 0.05 ), $N$ is sample sizes in regression model, $s\left\{\widehat{Y}_{h}\right\}$ means the standard deviation of the predicted mean value $\widehat{Y}_{h}$, SQRT means the square root operator, MSE $=\sum\left(Y_{i}-\widehat{Y}_{i}\right)^{2} /(N-2)$ is the mean square error with $\widehat{Y}_{i}=a+b X_{i}$, and $X_{h}, X_{i}$, and $\bar{X}$ are the random, observed, and averaged independentvariables, respectively. $Y_{i}$ and $\widehat{Y}_{i}$, however, are the random depend-variables responded to random variable $X_{i}$. $X$ and $Y$ variables are referred as particle diameter $d p$ and specific surface area SSA in this study. Eqs. (4) and (5) are derived from Walpole et al. (1998).

We applied the HRT model (ICRP, 1994) to estimate the internal exposure doses in different lung regions (Fig. 1B). The HRT model, varied with particle size ranges of $\mathrm{PM}_{0.18}$ and equilibrium time to each regional compartment and represented by a linear dynamic equation (Liao et al., 2006), was used to estimate surface area-based UFCP 


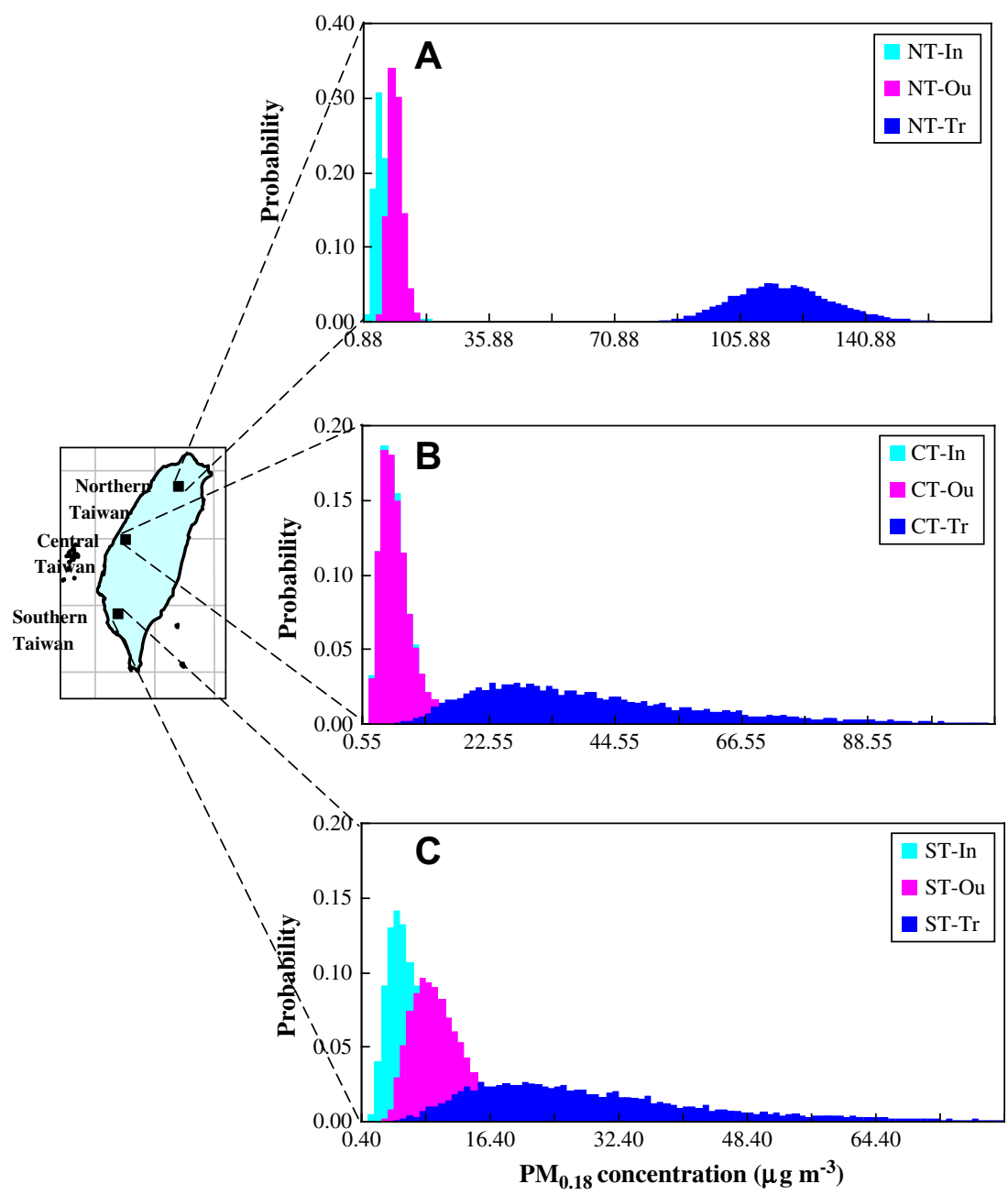

Fig. 2. Probability distribution of $\mathrm{PM}_{0.18}$ mass concentration for each setting. The full names of all the abbreviated words in the figure are presented in the main content, and all data are performed by lognormal distribution with geometric mean (GM) and geometric standard deviation (GSD), such as LN(GM, GSD).

concentration in lung alveolar-interstitial (AI) region. We solved the linear dynamic equation to obtain the mass lung/indoor $(\mathrm{L} / \mathrm{I})$ ratio based on an equilibrium state in each compartment. The specific fractional deposition $\left(d_{\mathrm{F}}\right)$ for $\mathrm{PM}_{0.18}$ in each compartment was then estimated, with a focus on the lung tissue of the lower respiratory tract (AI region). We also incorporated the MPPD model version 2 (CIIT Centers for Health Research, 2006) with HRT model (ICRP, 1994) to quantify the $d_{\mathrm{F}}$ value.

We reconstructed an exposure model based on surface area dosimetry, involving the active surface area concentration of UFCP $\left(\mathrm{SA}, \mathrm{m}^{2} \mathrm{~m}^{-3}\right.$ ), volume of air breathed ( $A B$, $\mathrm{m}^{3} \mathrm{~h}^{-1}$ ), time spent (TS, $\mathrm{h} \mathrm{d}^{-1}$ ), and exposure duration (ED, $d$ ),

$D=\mathrm{SA} \times \mathrm{AB} \times \mathrm{TS} \times \mathrm{ED}$,

with $\mathrm{SA}=\mathrm{C}_{\mathrm{UFCP}} \times \mathrm{SSA} \times d_{\mathrm{F}}=\mathrm{PM} \times f \times \mathrm{SSA} \times d_{\mathrm{F}}$, where $D$ is surface area-based cumulative dose of $\operatorname{UFCP}\left(\mathrm{m}^{2}\right), \mathrm{C}_{\mathrm{UFCP}}$ is the mass concentration of UFCP exposure and can be obtained from UFP concentration (PM) multiple by an apportion factor $(f)$ of UFCP to UFP, SSA is the specific surface area of size-specific UFCP, $d_{\mathrm{F}}$ is the deposition fraction deposited on AI region by HRT and MPPD models.

We treated $A B$ and $P M$ probabilistically and had lognormal distributions. The $f$ is assumed to be a solid value of 0.4 (ten Brink et al., 2005). The reliable values of factor $f$ in different settings are extremely difficult to obtain, if it is not impossible. Cass et al. (2000) and Ning et al. (2007) reported that the likelihood values of $f$ in urban area ranging from $0.44 \pm 0.12$ (mean $\pm \mathrm{sd}$ ) to $0.49 \pm 0.13$. Size-specific SSA can be obtained from our proposed particle surface area approach, TS is a scenario-specific constant value, ED is constant value of 365 days (i.e. 1-year duration for chronic exposure).

\subsection{Effect assessment}

Here we tested several target biomarkers from the literature by which limited data points can be constructed as surface area-based dose-response profiles. The neutrophil cells elevation effect (Renwick et al., 2004) is the available endpoints for assessing the precursor of adverse human health in the present study. Meanwhile, the 
Table 1

Summary of the relationships between carbon particles sizes and correspondent specific surface areas

\begin{tabular}{|c|c|c|}
\hline Particle diameter (nm) & $\operatorname{SSA}^{\mathrm{c}}\left(\mathrm{m}^{2} \mathrm{~g}^{-1}\right)$ & Reference \\
\hline \multicolumn{3}{|c|}{ Materials: Fine and ultrafine carbon black } \\
\hline $11.2 \pm 0.5$ & 456.7 & Tamaoki et al. (2004) \\
\hline $12-17(14.4 \pm 1.5)^{\mathrm{a}}$ & 272 & Stoeger et al. (2006) \\
\hline 14 & 300 & $\begin{array}{l}\text { Elder et al. (2005); Koike } \\
\text { and Kobayashi (2006); Stoeger } \\
\text { et al. (2006) }\end{array}$ \\
\hline 14 & 253.9 & Donaldson et al. (2002) \\
\hline 14.3 & 253.9 & Renwick et al. (2004) \\
\hline $14.3 \pm 0.6$ & 253.99 & Kim et al. (2003) \\
\hline 16 & 220 & Driscoll et al. (1996) \\
\hline $30-60(43.5 \pm 9.3)^{\mathrm{a}}$ & 43 & Stoeger et al. (2006) \\
\hline 51 & 30 & Stoeger et al. (2006) \\
\hline 56 & 45 & Koike and Kobayashi (2006) \\
\hline 70 & 37 & Elder et al. (2005) \\
\hline 95 & 20 & Koike and Kobayashi (2006) \\
\hline $250.4 \pm 16.1$ & 7.8 & Tamaoki et al. (2004) \\
\hline 260 & 7.9 & Donaldson et al. (2002) \\
\hline $260.2 \pm 13.7$ & 7.9 & $\begin{array}{l}\text { Kim et al. (2003); Renwick } \\
\text { et al. (2004) }\end{array}$ \\
\hline \multicolumn{3}{|c|}{ Materials: UFCP, Soot, DEP (diesel exhaust particles) } \\
\hline $7-12(9.3 \pm 1.5)^{a}$ & 807 & UFCP: Stoeger et al. (2006) \\
\hline $9^{\mathrm{b}}$ & 750 & UFCP: Kim et al. (2005) \\
\hline $8-14(10.7 \pm 1.9)^{\mathrm{a}}$ & 441 & Soot: Stoeger et al. (2006) \\
\hline $8-16(11.5 \pm 2.5)^{a}$ & 268 & Soot: Stoeger et al. (2006) \\
\hline $18-30(23.6 \pm 3.6)^{\mathrm{a}}$ & 108 & DEP: Stoeger et al. (2006) \\
\hline
\end{tabular}

a The mean and standard error values are estimated by using 10,000 times Monte Carlo simulations.

b The particle size should type error in original source by Kim et al. (2005), the original data is $90 \mathrm{~nm}$, whereas $9 \mathrm{~nm}$ in such situation should be reasonable.

c SSA: Specific surface area.

determination of neutrophil cells in plasma/tissue is usually used to identify the level of immune response while the cells in plasma/tissue exposed to UFCP/NPs.

We constructed the dose-response profiles by fitting Hill model to the published data on surface area-based inhaled UFCP dose-effects for neutrophil cells elevation effect (Fig. 1C),

$R(D)=\frac{R_{\max } \times D^{n}}{K_{0.5}^{n}+D^{n}}$

where $R_{\max }$ is the maximum measured response (fold for neutrophil cells elevation effect), $R(D)$ is the response for a specific surface area-based inhaled UFCP dose, $K_{0.5}$ is the cumulative surface area-based UFCP dose yielding half the maximal response of $R_{\max }\left(\mathrm{m}^{2}\right), D$ is the cumulative surface area-based UFCP dose deposited on the human lung AI region $\left(\mathrm{m}^{2}\right)$, and the exponent $n$ is a fitted Hill coefficient. A value of $n>1$ indicates positive cooperativity. We used Table Curve 2D (Version 5, AISN Software Inc., Mapleton, OR, USA) to optimize the dose-response profile with significance at $p<0.05$.

We treated the $K_{0.5}$ value in Eq. (7) probabilistically. The cumulative distribution function (CDF) of the predicted response function for a given surface area-based UFCP dose is expressed as a conditional CDF,

$P(R \mid D)=\Phi\left(\frac{R_{\max } \times D^{n}}{K_{0.5}^{n}+D^{n}}\right)$,

where $\Phi(\bullet)$ is the cumulative standard normal distribution.

\subsection{Risk characterization}

Risk characterization provides an estimate of risk for the specific subpopulation under study (Fig. 1D). The risk at a specific surface area-based inhaled UFCP dose of selected effect (neutrophil cells elevation effect) can be calculated as the UFCP dose multiplied by the conditional probability of selected effect on human lung. A joint probability function or exceedance profile describes the probability of exceeding the cumulative dose associated with the related response and can be expressed mathematically as,

$P(R, D)=P(D) \times P(R \mid D)$,

where $P(R, D)$ is the probabilistic risk for a certain cumulative dose $D, P(R \mid D)$ is the CDF of having surface area-based UFCP cumulative dose $D$ on human lung AI region, and $P(D)$ is the probability of surface area-based cumulative dose $D$ on human lung AI region.

We performed sensitivity analysis to identify the most significant parameters that are included in the uncertainty and variability analysis. The sensitivity of each variable relative to one another is assessed by calculating rank correlation coefficients between each input and output during simulations and then estimating each input contribution to the output variance and normalizing to $100 \%$. The MC simulation and sensitivity analysis are implemented using Crystal Ball software (Version 2000.2, Decisioneering, Inc., Denver, CO, USA).

\section{Results}

\subsection{Exposure estimations}

The indoor activities in three regions (NT-In, CT-In, and ST-In) had the lowest mass concentration distribution of $\mathrm{LN}\left(5.4 \mu \mathrm{g} \mathrm{m}^{-3}, 1.6\right)$, whereas outdoor activities, the highest value (LN $\left(9.3 \mu \mathrm{g} \mathrm{m}^{-3}, 1.5\right)$ ) appeared in ST-Ou setting, followed by NT-Ou (LN $\left.\left(8.8 \mu \mathrm{g} \mathrm{m}^{-3}, 1.3\right)\right)$ and CT-Ou ( $\left.\mathrm{LN}\left(5.4 \mu \mathrm{g} \mathrm{m}^{-3}, 1.6\right)\right)$ settings (Fig. 2). However, there is the higher $\mathrm{PM}_{0.18}$ value measured in NT region ( $\mathrm{LN}\left(116.2 \mu \mathrm{g} \mathrm{m}^{-3}\right.$, 1.1)) than those of in $\mathrm{CT}\left(\mathrm{LN}\left(36.1 \mu \mathrm{g} \mathrm{m}^{-3}, 1.7\right)\right)$ and $\mathrm{ST}$ $\left(\mathrm{LN}\left(26.4 \mu \mathrm{g} \mathrm{m}^{-3}, 1.8\right)\right)$ regions for $\mathrm{Tr}$ activity.

In SSA approach, SSA model $1(\ln Y=10.17-1.71 \ln X$, $R^{2}=0.98$, MSE $\left.=3.93 \times 10^{2}\right)$ can describes the relationships of all the data points, yet it cannot describe larger particle size with $d p>51 \mathrm{~nm}$ (Table 1; Fig. 3A). The SSA for UFCP $(d p=180 \mathrm{~nm})$ with $95 \% \mathrm{CI}$ is estimated to be $3.63\left(0_{-}\right.$ 14.3) $\mathrm{m}^{2} \mathrm{~g}^{-1}$, indicating that the modeled SSA for CB exists large variability. Result shows that there are large differences between estimated and observed (reference point: $\mathrm{SSA}=7.9 \mathrm{~m}^{2} \mathrm{~g}^{-1}$ at $d p=260 \mathrm{~nm}$ ) values on model 1.

SSA model $2\left(\ln Y=11.0-2.03 \ln X, R^{2}=0.98\right.$, $\mathrm{MSE}=3.82 \times 10^{2}, N=9$ ) shows better goodness-of-fit than SSA model 1 for the data points with $d p<51 \mathrm{~nm}$, indicating that more precise predictions are found in smaller particle size (Fig. 3B). On the other hand, SSA model $3(\ln Y=8.65-1.20$ $\left.\ln X, R^{2}=0.98, \mathrm{MSE}=5.81, N=6\right)$ is also found to describe better SSA relationships with larger $d p$ data points $(d p>51 \mathrm{~nm})$ than the SSA model 1 (Fig. 3B). Thus, the more exact SSA for UFCP $(d p=180 \mathrm{~nm})$ is estimated to be 11.2(8.47-14.0) $\mathrm{m}^{2} \mathrm{~g}^{-1}$ by using SSA model 3 (Fig. 3B). 


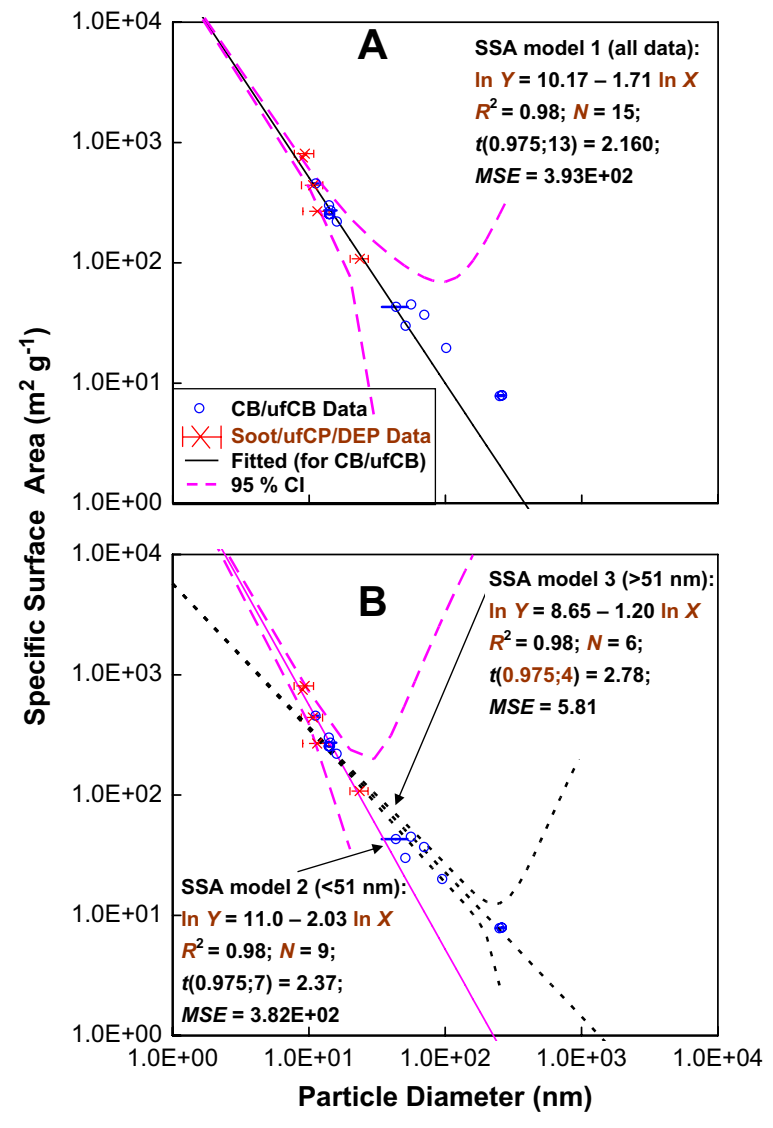

Fig. 3. (A) Linear fitted model (SSA model 1) with all data points and (B) refitted models (SSA model 2 for $d p<50 \mathrm{~nm}$ and model 3 for $d p>50 \mathrm{~nm}$ ) for specific surface area correlated with particle diameter. Error bars represent standard deviation from the mean.

The $A B$ values associated with different age groups and activities are shown in Table 2 . In exposure assessment, the $\mathrm{AB}$ values and TS parameters in Table 2 are significantly affecting the surface area-based dose estimations. The assumed TS parameters for the Adult, Youth, and Infant subgroups in indoor activity are 13,10 , and $8 \mathrm{~h}$, respectively. There are $8 \mathrm{~h}$ sleep activity for Adult and Youth subgroups that are also considered, whereas $14 \mathrm{~h}$ in sleep activity for Infant subgroup is reasonably assumed. For TS in outdoor and in-traffic activities, the value for Youth ( $6 \mathrm{~h}$ ) subgroup is higher than those of Adult ( $3 \mathrm{~h}$ ) and Infant (2 h) subgroups.

These results take into account the three age groups (Adult, Youth, and Infant) with four major activities (indoor, sleep, outdoor, and in-traffic) on a daily basis. Fig. $4 \mathrm{~A}$ presents the surface area-based UFCP dose for three age groups in NT, CT, and ST regions during one-year exposure based on subgroup-specific air breathed rates (Fig. 4B). Results indicate that the estimated doses for three age groups in NT region are higher than those in CT and ST regions. For NT region, there is highest median value of surface area-based UFCP dose for Adult $\left(0.0914 \mathrm{~m}^{2}\right)$, followed by Youth $\left(0.0756 \mathrm{~m}^{2}\right)$ and Infant $\left(0.0159 \mathrm{~m}^{2}\right)$, yet there is a wider range for Youth (95\% CI: 0.0191-0.1486 $\mathrm{m}^{2}$ ). Accordingly, the Adult or Youth subgroup in NT region posed as more potential risk than those of other settings.
Table 2

Air breathed rate (mean \pm standard derivation) and time spent parameters for Adult, Youth, and Infant subgroups using in the model

\begin{tabular}{llll}
\hline Activities & Adult $(A)^{\mathrm{c}}$ & Youth $(Y)^{\mathrm{c}}$ & Infant $(I)^{\mathrm{c}}$ \\
\hline Air breathed rate $\left(\mathrm{m}^{3} \mathrm{~h}^{-1}\right)^{\mathrm{a}}$ & & \\
Indoor & $1.07(0.156)$ & $0.753(0.229)$ & $0.31(0.06)$ \\
Sleep & $0.385(0.092)$ & $0.312(0.073)$ & $0.15(0.03)$ \\
Outdoor & $1.105(0.148)$ & $0.937(0.483)$ & $0.31(0.06)$ \\
In-traffic & $1.105(0.148)$ & $0.937(0.483)$ & $0.31(0.06)$ \\
Time spent $\left(\mathrm{h} \mathrm{d}^{-1}\right)^{\mathrm{b}}$ & & & \\
Indoor & 13 & 10 & 8 \\
Sleep & 8 & 8 & 14 \\
Outdoor & 1 & 4 & 1 \\
In-traffic & 2 & 2 & 1 \\
\hline
\end{tabular}

a Data are adopted from ICRP66 report (ICRP, 1994).

b Data are reasonable assumed for people lived in Taiwan.

c Adult $(A)$ denotes the age greater than 18 years old, Youth $(Y)$ denotes the age between 5 and 17 years old, and Infant $(I)$ denotes the age less than 1 year old. The age groups of Adult, Youth, and Infant are defined from ICRP66 report (ICRP, 1994).

The $d_{\mathrm{F}}$ value for UFCP with $180 \mathrm{~nm}$ particle size deposited on AI regions was estimated to be 0.166 by HRT model (Fig. 4C). Results, however, also showed the entire distributions of $d_{\mathrm{F}}$ values with polydisperse particles $(d p<10 \mu \mathrm{m})$ by MPPD model (estimated $d_{\mathrm{F}}=0.124$, Fig. 4D). Taken together, we suggested that the $d_{\mathrm{F}}$ value for UFCP deposited on the human lung $\mathrm{AI}$ region was accounted for $0.145 \pm 0.021$.

\subsection{Dose-response curves}

The maximum response $R_{\max }$ for neutrophil cells elevation effect is estimated to be 47.4 fold compared to control (Fig. 5). The Hill coefficient $(n)$ for the current fitting is 1.13 with a $R^{2}=0.91$. The specific cumulative dose yielding half of maximal response $K_{0.5}$ for neutrophil cells elevation effect was estimated at $2.96 \times 10^{-2} \mathrm{~m}^{2}$.

\subsection{Risk profiling}

Table 3 gives that the exceedance risk (ER) matrix under 10 and 50\% probabilities (ER10 and ER50) for surface areabased UFCP dose with selected endpoints onto each setting. Youth subgroup in NT region posed significant potential risk, whereas the lowest risk is appeared for Infant subgroup in ST region (Fig. 6A, B). Neutrophil cells elevation effect for Youth subgroup in NT region shows the highest potential risk, indicating the median ER10 values are 39.6 (36.4-42.9) fold compared to control.

There are highest values of median ER50 for Adult subgroup in NT region, showing 37.3 (34.7-39.9) fold compared to control for the neutrophil cells elevation effect. In contrary, for Infant subgroup in ST region, there are 15.5 (13.2-17.7) and 10.1 (7.7-12.4) fold compared to control based on the ER10 and ER50 for neutrophil cells elevation effect, respectively (Table 3 ).

\subsection{Sensitivity analysis}

Sensitivity analysis shows that the PM in in-traffic activity (PM/Tr), PM in indoor activity (PM/In), and $d_{\mathrm{F}}$ value 

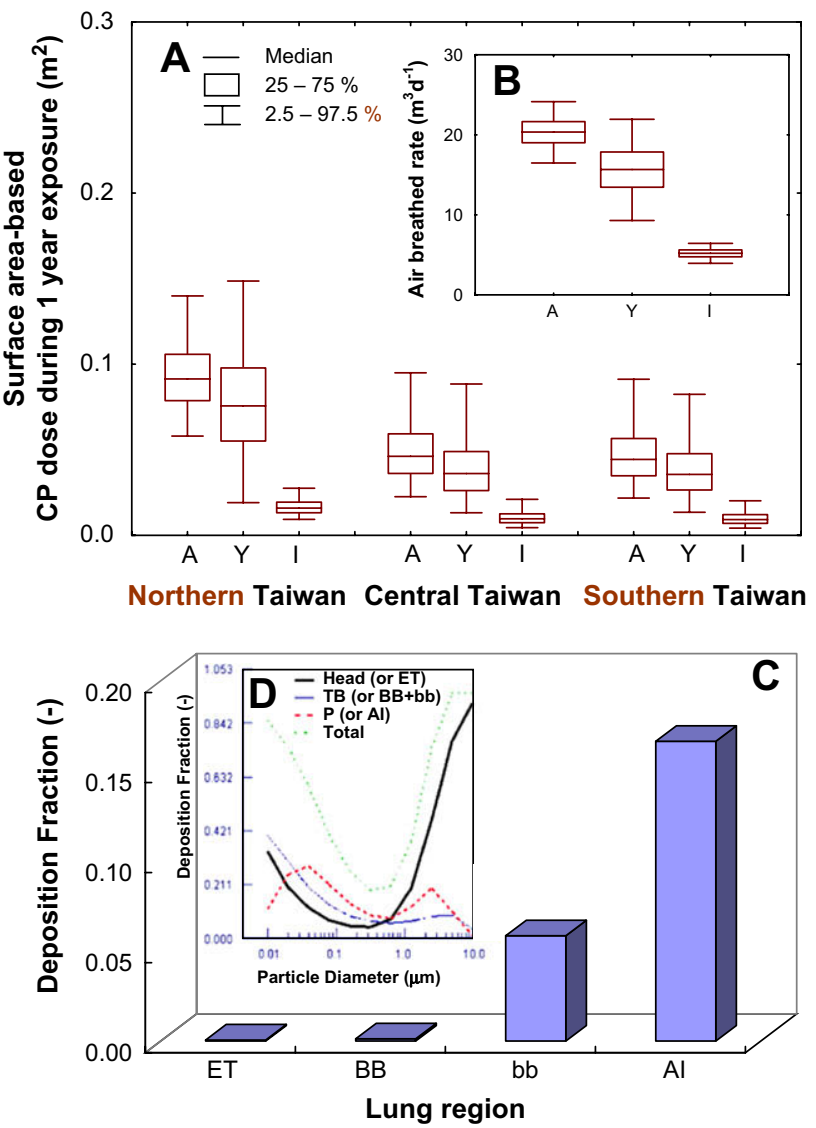

Fig. 4. Model estimations for air breathed rate (A), UFCP cumulative dose (B), and deposition fraction estimations for HRT (C) and MPPD (D) models. ET, BB, bb, AI, $\mathrm{TB}$, and $\mathrm{P}$ are the abbreviated words for nasal passage, bronchial, bronchiolar, alveolar-interstitial, tracheobronchial, and pulmonary regions, respectively.

(DF) for Adult subgroup in three regions are the major factor (Fig. 7A-C; 89.4-92.5\% of variance), whereas the PM in indoor activity (PM/In) is the affecting factor for Infant subgroup in Taiwan (Fig. 7G-I; 46.3-65.4\% of variance). Results also show that the PM in in-traffic activity (PM/Tr) and the air breathed rate in in-traffic activity $(\mathrm{AB} / \mathrm{Tr})$ are the most two factors to influence the potential risks for Youth subgroup in Taiwan, except for northern Taiwan (Fig. 7D-F). Only one major factor $(\mathrm{AB} / \mathrm{Tr}, 78.8 \%$ of variance) is found. Summarize the results of sensitivity analyses, we could find that $\mathrm{PM} / \mathrm{Tr}, \mathrm{PM} / \mathrm{In}, \mathrm{DF}$, and $\mathrm{AB} / \mathrm{Tr}$ variables were the significant factors affecting the risk estimation.

\section{Discussion}

\subsection{SSA approach and dose estimates}

Theoretically, the slope $(b)$ in the SSA fitted model must be -1 based on Eq. (1). However, our results show that $b$ estimates ranged from -2.0 (SSA model 2 with $d p<51 \mathrm{~nm}$ ) to -1.2 (SSA model 3 with $d p>51 \mathrm{~nm}$ ), indicating that the original SSA data points measured by BET method might have high variability/uncertainty caused by shape and porosity. UFCP, soot, and diesel exhaust particle
(DEP) adopted from Kim et al. (2005) and Stoeger et al. (2006) will also fall within the estimation range of SSA model 1 . We successfully provided the evidence for carbonaceous materials (i.e. CB, CP, DEP, and soot) to verify the intrinsic SSA-dp relationships. However, our proposed SSA- $d p$ relationships could not be applied for other materials or metals, even the regression interceptions and slopes

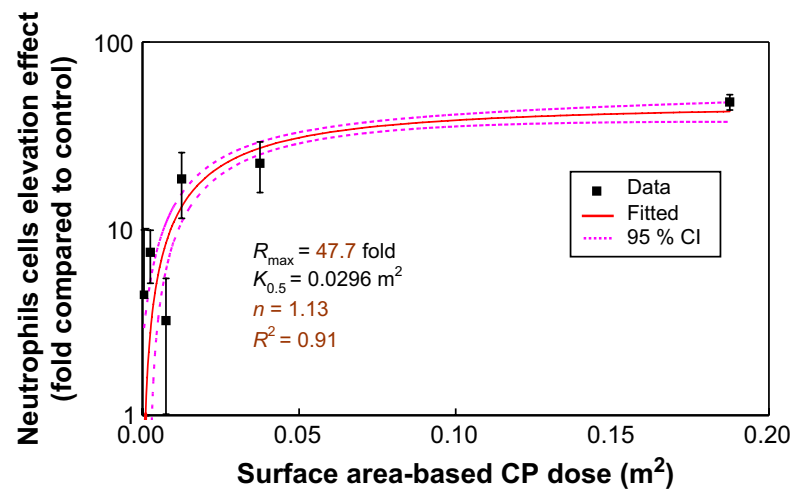

Fig. 5. Dose-response profiles optimally fitted by a three parameters Hill equation model with 95\% confidence intervals for neutrophil cells elevation effect. Error bars represent standard deviation from the mean. 
Table 3

ER50 and ER10 estimates for Adult, Youth, and Infant subgroups based on Neutrophil cells elevation effect (fold compared to control)

\begin{tabular}{llll}
\hline Location & Adult $(A)$ & Youth $(Y)$ & Infant $(I)$ \\
\hline ER50 & & & \\
NT & $\mathbf{3 7 . 3 ( 3 4 . 7 - 3 9 . 9})^{\mathrm{a}}$ & $35.5(33.1-37.8)$ & $15.8(13.5-18.0)$ \\
CT & $29.7(27.6-31.8)$ & $26.5(24.4-28.6)$ & $10.5(8.2-12.9)$ \\
ST & $29.2(27.1-31.1)$ & $26.4(24.2-28.5)$ & $10.1(7.7-12.4)$ \\
ER10 & & & \\
NT & $\mathbf{3 9 . 6 ( 3 6 . 4 - 4 2 . 9})^{\mathrm{a}}$ & $\mathbf{3 9 . 6 ( 3 6 . 4 - 4 2 . 9})^{\mathrm{a}}$ & $20.2(18.1-22.4)$ \\
CT & $35.2(32.9-37.6)$ & $33.8(31.5-36.0)$ & $16.0(13.8-18.3)$ \\
ST & $34.7(32.4-37.0)$ & $33.2(31.0-35.4)$ & $15.5(13.2-17.7)$ \\
\hline
\end{tabular}

a The highest values are in bold face.

might be varied enormously compared to other studies (Brown et al., 2007; Liao et al., 2007).

Our proposed SSA model also described well for UFCP, soot, and DEP for $d p$ ranging from 9.3 to $23.6 \mathrm{~nm}$. We suggested that SSA model 2 was better applied for $d p$ ranging from 9 to $24 \mathrm{~nm}(\mathrm{RMSE}=19.5)$, whereas SSA model 3 was better used for $d p$ ranging from 51 to $170 \mathrm{~nm}$ $($ RMSE $=2.41)$. Although the target size was greater than the highest diameter of $170 \mathrm{~nm}$, the estimated RSE value was only $21.5 \%$ for $d p=180 \mathrm{~nm}$. We thus suggested that the fitted SSA model 2 could be applied to estimate the SSA of target particle size of $d p=180 \mathrm{~nm}$.

Meanwhile, the parameters of PM level (UFP concentration), specific surface area, deposition fraction, air breathed rate, and time spent in the proposed exposure model were considered as regional-, size- and scenariodependent variables. Moreover, the apportion factor of UFCP to UFP and exposure duration were constants based on model assumptions (ICRP, 1994; ten Brink et al., 2005). Therefore, the Adult subgroup in NT region had the maximum median of UFCP dose based on the proposed settings, whereas Youth subgroup in NT region had the widest ranges of uncertainty associated with median value.

\subsection{Quantification of risk and control strategy}

Through the risk estimates of these preliminary health effects, researchers or decision makers could further understand the causing factor for tumor or other chronic diseases for human expose to UFCP or emerging nanoparticles (NP). Nevertheless, this work had been studied based on several bioassays correlated to UFCP/NP. It was believed that the rising issues for human health would be noteworthy in the near future (Nel et al., 2006).

Either air breathed rate in in-traffic activity or PM level in in-traffic activity was the major factor affecting the cumulative dose of UFCP for all settings. Because the air breathed rate in in-traffic and outdoor actives had the same impact, the major factor affecting final result was the time spent for in-traffic activity. Hence, the recommended strategy for decreasing the potential risk was to reduce the time spent for in-traffic activity, implicating that human longer time spent for in-traffic activity had higher human health adverse effect. The related epidemiological study also proved this argument (Chen et al., 2005).
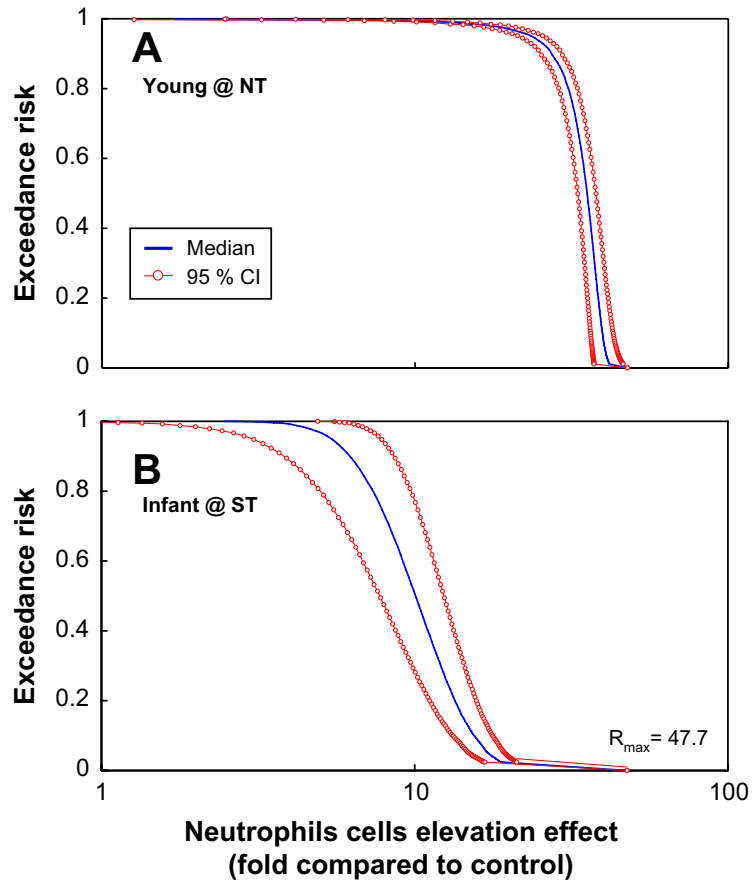

Fig. 6. Estimate exceedance risk curves with $95 \%$ confidence intervals for neutrophil cells elevation effect (A, B). Figures A and B describe the neutrophil cells elevation effects on maximum and minimum surface areabased CP doses. Meanwhile, the abbreviated words NT, CT, and ST present northern, central, and southern Taiwan.

Reducing the PM level in in-traffic activity was suggested to be the secondary strategy for reducing the human health risk. This strategy, however, was almost an expensive, complex and time-consuming task. Mobile sources emissions standard legislation and transportation management (McCarthy et al., 2006) methods were usually the issues to reduce the PM level in in-traffic activity. Moreover, bio-diesel or alcohol-gasoline additives uses were the novel method to reduce the PM level in intraffic activity (Durbin et al., 2007). Previous studies revealed that there were $30-50 \%$ and $5-15 \%$ of PM reduction for pure biodiesel (B100) and the blend of $20 \%$ biodiesel with $80 \%$ fossil diesel (B20), respectively (Durbin et al., 2007).

Many researches reported the real-time carbon content (e.g. black carbon or elemental carbon) measurement for ambient air (Petzold et al., 1997; Kirchstetter et al., 2008) or diesel particulate matter (Fruin et al., 2004) by using Aethalometer. The principle of detecting carbon content was based on the changing optical absorption of light transmitted through accumulated particle on filter. Petzold et al. (1997) reported a simple model to describe the relationship between light scattering effect and carbon content. Kirchstetter et al. (2008) found an interesting weekly cycle for black carbon concentration in California implying that the residents lived in the area exposed to high human health on the weekday (Monday-Friday) periods than that on the weekend (Sunday and Saturday). Therefore, we might predict and present the potential health risk to human through combining our assessment model with 

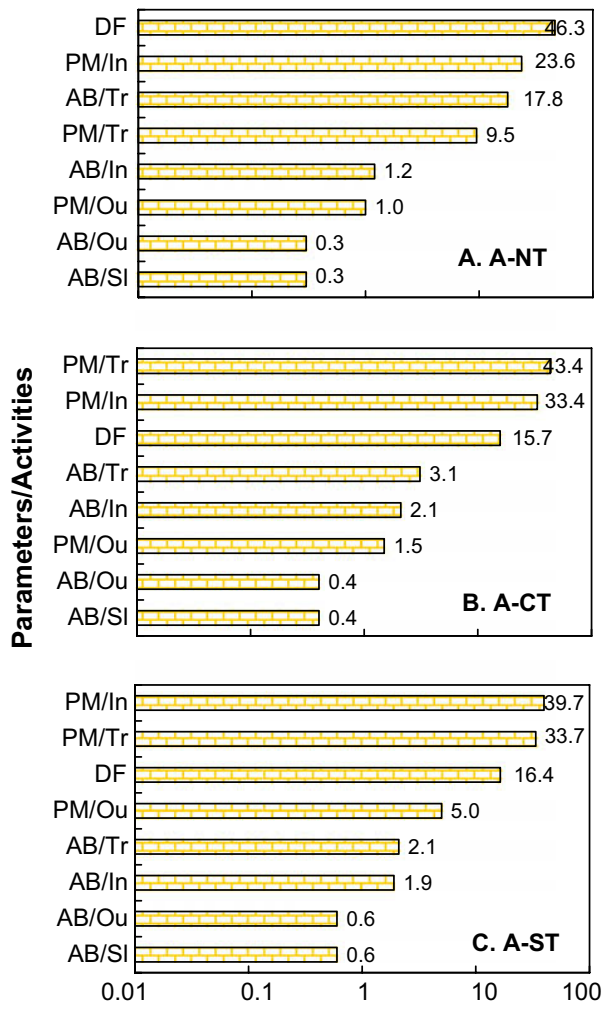
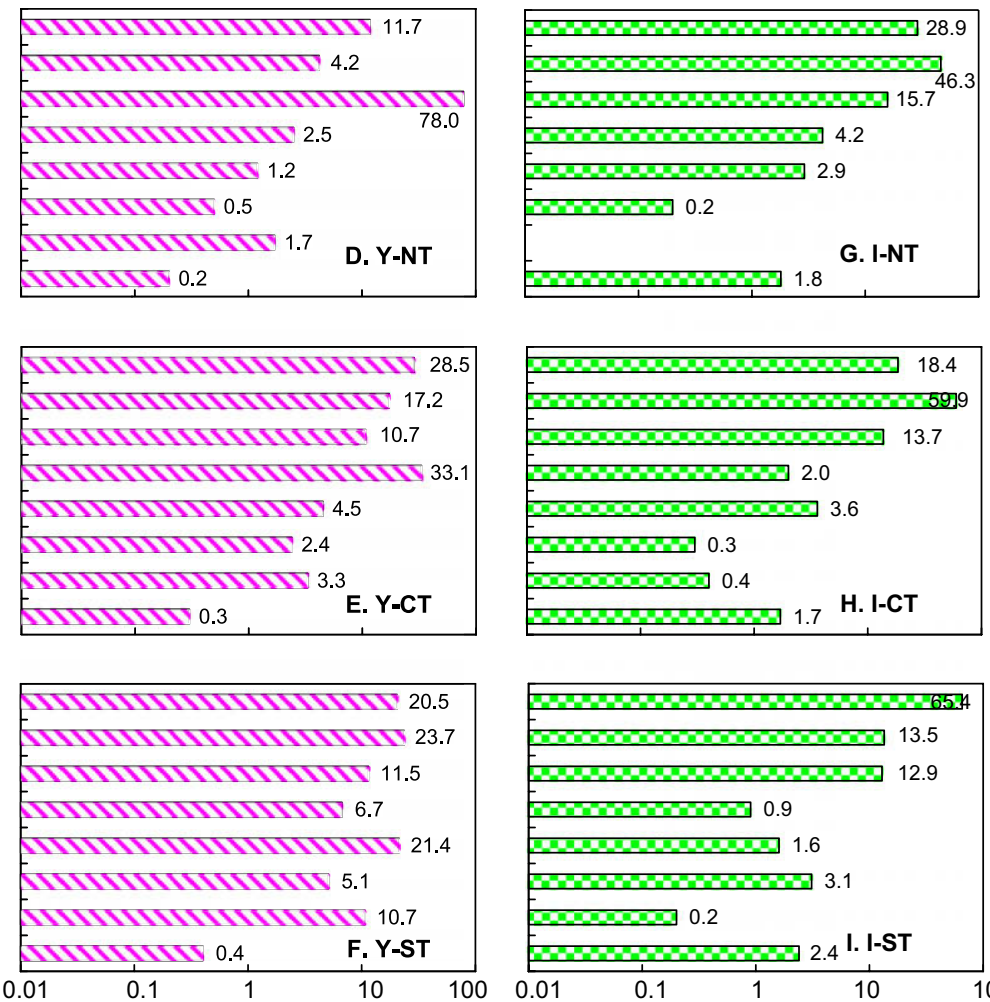

Measured by contribution to variance (\%)

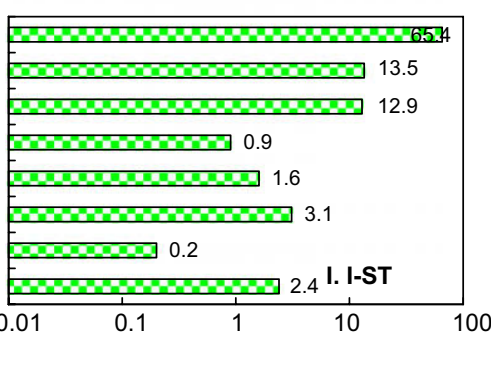

Fig. 7. Sensitivity analysis results of the contribution to variance for each setting. The full names of all the abbreviated words in the figure are presented in the main content.

atmospheric carbon particle real-time measurement technology in the future.

\section{Conclusions}

We introduced an approach to estimate the cumulative surface area-based dose deposited on human lung AI region of UFCP emitted from ambient environment. We employed HRT and MPPD models to successfully obtain the sizespecific deposition faction for human lung regions. Surface area dose estimations of UFCP were obtained through the relationship between particle size and surface area. We successfully constructed the suitable dose-response profiles using the neutrophil cells elevation effect to describe the relationships between surface area-based UFCP dose and human health effects. Our results show that Adult and Youth subgroup in northern Taiwan region posed the highest potential risk, indicating that the median $10 \%$ exceedance risks are 39.6 (95\%Cl: 36.4-42.9) fold compared to control based on neutrophil cells elevation effect. Sensitivity analyses show that PM/Tr, PM/In, DF, and $\mathrm{AB} / \mathrm{Tr}$ variables were the significant factors affecting the risk estimation. These results provide a preliminary assessment model to estimate the exceedance risk profiles for inhaling UFCP-induced human adverse effect for specific groups. Furthermore, we might link our proposed model and new real-time measurement technology for atmospheric UFCP to predict the potential human health risk in the near future.

\section{References}

Brown, S.C., Kamal, M., Nasreen, N., Baumuratov, A., Sharma, P., Antony, V. B., Moudgil, B.M., 2007. Influence of share, adhesion and simulated lung mechanics on amorphous silica nanoparticle toxicity. Advanced Powder Technology 18, 69-79.

Brunauer, S., Emmett, P.H., Teller, E., 1938. Absorption of gases in multimolecular layers. Journal of the American Chemical Society 60, 309-319.

ten Brink, H., Hoek, G., Khlystov, A., 2005. An approach to monitor the fraction of elemental carbon in the ultrafine aerosol. Atmospheric Environment 39, 6255-6259.

Cass, G.B., Hughes, L.A., Bhave, P., Kleeman, M.J., Allen, J.O., Salmon, L.G., 2000. The chemical composition of atmospheric ultrafine particles. Philosophical Transactions of the Royal Society of London A 358, 2581-2592.

Chen, J.C., Chen, Y.J., Chang, W.P., Christiani, D.C., 2005. Long driving time is associated with haematological markers of increase cardiovascular risk in taxi divers. Occupational and Environmental Medicine 62, 890-894.

Chio, C.P., 2005. Chemical Compositions and Source Contributions of $\mathrm{PM}_{2.5}$ and $\mathrm{PM}_{2.5-10}$ for Urban and Coastal Areas in Central Taiwan. PhD thesis, National Chung Hsing University, Taichung, Taiwan, ROC.

Chio, C.P., Chen, S.C., Chiang, K.C., Chou, W.C., Liao, C.M., 2007. Oxidative stress risk analysis for exposure to diesel exhaust particle-induced reactive oxygen species. Science of the Total Environment 387,113-127.

Chow, J.C., Watson, J.G., 2006. Ultrafine particles and health effects. Presented at Workshop on Recent Advances in Aerosol Measurement, National Central University, and Environmental Protect Administration. Taipei, Taiwan, June 6, 2006, pp. 1-11.

CIIT Centers for Health Research, 2006. Multiple-path particle dosimetry (MPPD) model version 2 software. Available from: http://www.ciit.org.

Donaldson, K., Brown, D., Clouter, A., Duffin, R., MacNee, W., Renwick, L., Tran, L., Stone, V., 2002. The pulmonary toxicology of ultrafine particles. Journal of Aerosol Medicine 15, 213-220.

Driscoll, K.E., Carter, J.M., Howard, B.W., Hassenbein, D.G., Pepelko, W., Baggs, R.B., Oberdörster, G., 1996. Pulmonary inflammatory, 
chemokine, and mutagenic responses in rats after subchronic inhalation of carbon black. Toxicology and Applied Pharmacology 136 372-380.

Durbin, T.D., Cock III, D.R., Sawant, A.A., John, K., Miller, J.W., Holden, B.B., Hegeson, N.L., Jack, J.A., 2007. Regulated emission s from biodiesel fuels from on/off-road applications. Atmospheric Environment 41, 5647-5658.

Elder, A., Gelein, R., Finkelstein, J.N., Driscoll, K.E., Harkema, J., Oberdörster, G., 2005. Effects of subchronically inhaled carbon black in three species. I. Retention kinetics, lung inflammation, and histopathology. Toxicological Sciences 88, 614-629.

Fine, P.M., Chakrabarti, B., Krudysz, M., Schauer, J.J., Sioutas, C., 2004. Diurnal variations of individual organic compound constituents of ultrafine and accumulation mode particulate matter in the Los Angeles basin. Environmental Science and Technology 38, 12961304.

Fruin, S.A., Winer, A.M., Rodes, C.E., 2004. Black carbon concentrations in California vehicles and estimation of in-vehicles diesel exhaust particulate matter exposure. Atmospheric Environment 38, 4123-4133.

Hwang, J.S., Hu, T.H., Chan, C.C., 2004. Air pollution mix and emergency room visits for respiratory and cardiac diseases in Taipei. Journal of Data Science 2, 311-327.

IARC, 1996. Printing Processes, Printing Inks, Carbon Black, and Some Nitro Compounds. IARC (International Agency for Research on Cancer), Lyon.

ICRP, 1994. Human Respiratory Tract Model for Radiological Protection, a Report of a Task Group of the International Commission on Radiological Protection. ICRP Publication/Elsevier, New York.

Kim, H., Liu, X., Kobayashi, T., Kohyama, T., Wen, F.Q., Romberger, D.J., Conner, H., Gilmour, P.S., Donaldson, K., MacNee, W., Rennard, S.I. 2003. Ultrafine carbon black particles inhibit human lung fibroblastmediated collagen gel contraction. American Journal of Respiratory Cell and Molecular Biology 28, 111-121.

Kim, Y.M., Reed, W., Lenz, A.G., Jaspers, I., Silbajoris, R., Nick, H.S., Samet, J. M., 2005. Ultrafine carbon particles induce interleukin- 8 gene transcription and p38 MAPK activation in normal human bronchial epithelial cells. American Journal of Physiology - Lung Cellular and Molecular Physiology 288, 432-441.

Kirchstetter, T.W., Aguiar, J., Tonse, S., Fairley, D., Novakov, T., 2008. Black carbon concentrations and diesel vehicle emission factors derived from coefficient of haze measurements in California: 1967-2003. Atmospheric Environment 42, 480-491.

Koike, E., Kobayashi, T., 2006. Chemical and biological oxidative effects of carbon black nanoparticles. Chemosphere 65, 946-951.

Lee, C.G., Yuan, C.S., Chang, J.C., Yuan, C., 2005. Effects of aerosol species on atmospheric visibility in Kaohsiung city, Taiwan. Journal of the Air and Waste Management Association 55, 1031-1041.

Li, C.S., Lin, C.H., 2003. Carbon profile of residential indoor $\mathrm{PM}_{1}$ and $\mathrm{PM}_{2.5}$ in the subtropical region. Atmospheric Environment 37, 881-888.

Liao, C.M., Chen, S.C., Chen, J.W., Liang, H.M., 2006. Contributions of Chinese-style cooking and incense burning to person exposure and residential PM concentrations in Taiwan region. Science of the Total Environment 358, 72-84.

Liao, C.M., Chiang, Y.H., Chio, C.P., 2007. Assessing the airborne titanium dioxide nanopartile-related exposure hazard at workplace. Journal of Hazardous Materials. doi:10.1016/j.jhazmat.2008.05.020.

Mauderly, J.L., Cheng, Y.S., Hoover, M.D., Yeh, H.C., Johnson, N.F., 2000 Particles inhaled in the occupational setting. In: Gehr, P., Heyder, J. (Eds.), Particle-Lung Interactions. Marcel Dekker, NY, pp. 89-170.

McCarthy, M.C., Eisinger, D.S., Hafner, H.R., Chinkin, L.R., Roberts, P.T., Black, K.N., Clark, N.N., McMurry, P.H., Winer, A.M., 2006. Particulate matter: a strategic vision for transportation-related research. Environmental Science and Technology 40, 5593-5599.

Morfeld, P., Büchte, S.F., McCunney, R.J., Piekarski, C., 2006. Lung cancer mortality and carbon black exposure: uncertainties of SMR analyses in a cohort study at a German carbon black production plant. Journal of Occupational and Environmental Medicine 48, 1253-1264.

Nel, A.E., Xia, T., Mädler, L., Li, N., 2006. Toxic potential of materials at the nanolevel. Science 311, 622-627.

Nerriere, É., Zmirou-Navier, D., Blanchard, O., Momas, I., Ladner, J., Moullec, Y. L., Personnaz, M., Lameloise, P., Delmas, V., Target, A., Desqueyroux, H., 2005. Can we used fixed ambient air monitors to estimate population long-term exposure to air pollutants? The case of spatial variability in the Gentox ER study. Environmental Research 97, 32-42.

Ning, Z., Geller, M.D., Moor, K.F., Sheesley, R.J., Schauer, J.J., Sioutas, C., 2007. Daily variation in chemical characteristics of urban ultrafine aerosols and inference of their sources. Environmental Science and Technology 41, 6000-6006.

Oberdörster, G., Oberdörster, E., Oberdörster, J., 2005. Nanotoxicology: an emerging discipline evolving from studies of ultrafine particles. Environmental Health Perspectives 113, 823-839.

Petzold, A., Kopp, C., Niessner, R., 1997. The dependence of the specific attenuation cross-section on black carbon mass fraction and particle size. Atmospheric Environment 31, 661-672.

Renwick, L.C., Brown, D., Clouter, A., Donaldson, K., 2004. Increased inflammation and altered macrophage chemotactic responses caused by two ultrafine particle types. Occupational and Environmental Medicine 61, 442-447.

Stoeger, T., Reinhard, C., Takenaka, S., Schroeppel, A., Karg, E., Ritter, B., Heyder, J., Schulz, H., 2006. Instillation of six different ultrafine carbon particles indicates a surface area threshold dose for acute lung inflammation in mice. Environmental Health Perspectives 114, 328-333.

Tamaoki, J., Isono, K., Takeyama, K., Tagaya, E., Nakata, J., Nagai, A., 2004. Ultrafine carbon black particles stimulate proliferation of human airway epithelium via EGF receptor-medicated signaling pathway. American Journal of Physiology - Lung Cellular and Molecular Physiology 287, 1127-1133.

Tsai, P.J., Shieh, H.Y., Hsieh, L.T., Lee, W.J., 2001. The fate of PAHs in the carbon black manufacturing process. Atmospheric Environment 35, 3495-3501.

Utell, M.J., Samet, J.M., 1996. Airborne particles and respiratory disease: clinical and pathogenetic considerations. In: Wilson, R., Spengler, J.D. (Eds.), Particles in Our Air: Concentrations and Health Effects. Harvard University Press, Cambridge, MA, pp. 169-188.

Walpole, R.E., Myers, R.H., Myers, S.L., 1998. Probability and Statistics for Engineers and Scientists, sixth ed. Prentice Hall, NJ.

Watson, J.G., Chow, J.C., Chen, L.W.A., 2006. Problems and solutions in monitoring PM carbon components. Presented at Workshop on Recent Advances in Aerosol Measurement, National Central University, and Environmental Protect Administration. Taiwan, Taipei. June 6, 2006, pp. 1-18.

Wellmann, J., Weiland, S.K., Neiteler, G., Klein, G., Straif, K., 2006. Cancer mortality German carbon black workers 1976-1998. Occupational and Environmental Medicine 63, 513-521.

Wilson, A.M., Wake, C.P., Kelly, T., Sallway, J.C., 2005. Air pollution, weather, and respiratory emergency room visits in two northern New England cities: an ecological time-series study. Environmental Research 97, 312-321.

Yang, Q., Chen, Y., Krewski, D., Burnett, R.T., Shi, Y., McGrail, K.M., 2005. Effect of short-term exposure to low levels of gaseous pollutants on chronic obstructive pulmonary disease (COPD) hospitalizations. Environmental Research 99, 99-105. 